\title{
A BEJAHUNG NAS CONEXÕES DA PSICANÁLISE
}

\author{
Oswaldo França Neto*
}

\section{RESUMO}

Por meio dos temas freudianos da "afirmação" (Bejahung) e das "negaçôes", este texto visa explorar consequiências da proposta feita por Lacan para ultrapassarmos as teorias freudianas da castração e do Édipo. Como referência importante, utilizaremos alguns conceitos matemáticos pertencentes à teoria dos conjuntos, na forma com que foram trabalhados por Alain Badiou.

Palavras-chave: afirmação, negação, castração, sintoma, singularidade

\section{AbSTRaCt}

THE BEJAHUNG IN THE CONNECTIONS OF THE PSYCHOANALYSIS

By using freudian themes of "affirmation" (Bejahung) and "negation", this text seeks to explore the consequences of Lacan's proposal to go beyond Freud's castration and Oedipal theories. We will employ certain mathematical concepts pertinent to group theories as an important reference, as seen and employed in the work of Alain Badiou.

Keywords: affirmation, negation, castration, symptom, singularity

A dupla negação/afirmação está presente em Freud desde o início de seus trabalhos, que colocaram, no centro das discussões, as diferentes formas de defesa de que o aparelho psíquico lança mão face ao que deve ser negado, escondido, rechaçado. No inconsciente não existe a palavra "não" (Freud, 1925/1976: 300). Lá é o império do "sim", onde tudo é permitido, independentemente de responder ou não à lógica da razão ou às leis morais. Em oposição a ele teríamos a consciência, lugar por excelência do "não", onde as afirmações do inconsciente só

\footnotetext{
* Professor do Programa de Pós-graduação em Estudos Psicanalíticos (UFMG), Psicanalista.
} 
poderiam manifestar-se se devidamente camufladas, ou então explicitamente sob a forma de uma negação: "Agora o senhor vai pensar que quero [...], mas realmente não tenho essa intenção" (ibid: 295). Ou seja, o sujeito do desejo somente pode se fazer presente na consciência ao inventar, por meio de uma negativa, um compromisso acerca daquilo que recusa em si mesmo. Os termos utilizados por Freud para falar de negaçôes ou defesas com relação ao que se impõe de "dentro" são inúmeros. Podemos citar Verdrängung (recalque), Verleugnung (recusa), Verneinung (denegação), Verwerfung (rejeição), Ablehnen (afastar, declinar), Aufheben (suprimir, abolir), retração de Besetzung (investimento), retração de Bedeutung (significação) ${ }^{1}$, entre outros. Alguns destes, com os desdobramentos da teoria, passaram a ser considerados fundamentais, já que determinantes da maneira como o sujeito viria a se apresentar enquanto estrutura clínica. Dessa forma, principalmente a partir da leitura que Lacan faz do texto freudiano, passamos a relacionar a Verdrängung com a neurose, a Verleugnung com a perversão e a Verwerfung com a psicose.

O desejo, que para Lacan seria a essência do homem, não deixa também de apresentar sua face defensiva. Em 1960, Lacan sustenta que o perverso, assim como o neurótico, "se defende, à sua maneira, em seu desejo", visto que "o desejo é uma defesa, proibição de ultrapassar um limite de gozo" (Lacan, 1960/1998: 839). Alcança-se a lei do desejo a partir da recusa do gozo, não sendo o desejo nada mais do que a "escala invertida" do que foi recusado (ibid: 841).

A partir da concepção de Letra proposta por Lacan, poderíamos vir a postular algo próximo a uma ontologia negativa, onde, via matema (que, por definição, está marcado pela foraclusão da afirmação que o constitui), atingiríamos uma negatividade pura, uma completa apreensão pelo saber ${ }^{2}$. Outra possibilidade seria, ao contrário, trabalharmos sob a perspectiva de uma pura afirmação, uma espécie de inscrição gozosa imanente, alheia a qualquer compromisso com as pretensões do conhecimento. Alain Badiou, em livro publicado na França em 1997, traz a público uma curta, porém intensa correspondência com Gilles Deleuze, onde se desenvolve um embate entre suas teorias. Em certo momento, Badiou reconhece estar na defesa de ser o verdadeiro pensador da imanência (afirmação) (Badiou, 1997: 43-4), o ponto central da controvérsia, cada um reputando ao outro uma transcendência travestida em imanência (ibid: 58-9).

J.-A. Miller, em aula proferida em 28 de maio de 1987 (e publicada pela primeira vez em 1993), vai trabalhar a impossibilidade da comunicação por meio do que ele chamou de "foraclusão generalizada" (Miller, 1987/1993). Esta nos leva a pensar em um Outro desencarnado, pura negatividade simbólica, onde se veria comprometida a possibilidade de existência de um sujeito. Miller vai aproxi- 
mar essa expressão com a afirmação de Lacan de que a "relação sexual não existe", propondo que só o sintoma, enquanto aparelho de gozo (afirmação pura?), poderia tornar possível o que entendemos por comunicação. A psicanálise, assim, ao reconhecer o sintoma, colocar-se-ia como contraponto a uma sociedade marcada pela autonomia do simbólico, oferecendo ao sujeito uma possibilidade de exsistência. Em recente livro, Le siècle, Badiou propõe o termo "subtração" para falar de um resgate do real frente a uma sociedade que teria se voltado para um "niilismo passivo", ou seja, "hostil a toda ação como a todo pensamento" (Badiou, 2005: 98 [tradução minha]).

\section{DENEGAÇÃo}

No texto $A$ denegação, Freud discute o que poderíamos propor como sendo a maneira como se constitui o aparelho psíquico, a partir de dois juízos: atribuição e existência. Nenhum dos dois teria, a rigor, preocupaçōes ontológicas, referindo-se exclusivamente ao próprio aparelho e suas representaçôes, sem preocuparem-se com a existência concreta ou não dos objetos do mundo (tema por excelência da filosofia). O primeiro juízo, de atribuição, atribui a algo o predicado de ser bom (dentro) ou mau (fora), demarcando assim os limites originários do aparelho. O segundo juízo, de existência, colocaria à prova se algo que está dentro (e aí já estaríamos no campo da representação) corresponderia exatamente a aquilo que se apresenta do lado de fora. Esse segundo juízo teria a função de pontuar que o objeto em questão não corresponde exatamente ao procurado, o que preservaria o aparelho no registro da falta.

Falando em termos míticos, e não propriamente como um momento genético (Lacan, 1954/1998: 384), na operação mais primordial de todas, aquela pela qual se estabeleceria o primeiro "dentro", encontramos a inscrição da Bejahung, ou Urbejahung ("afirmação primordial”). Em contraposição a esta teríamos uma Austossung, ou "expulsão", que, segundo Lacan, "constituiria o real na medida em que ele é o domínio que subsiste fora da simbolização" (ibid: 390). A denegação, ou o "não" da consciência, seria o "sucessor" (Nachfolger) dessa operação de expulsão (Freud, 1925/1976: 300). Vemos assim que a Bejahung, aquilo que mais próximo poderíamos ter de uma afirmação pura, infinita, carreia consigo uma negação (expulsão). Se ela é pura afirmação, algo, no entanto, tem que ser expulso para que ela possa constituir-se como tal. Paradoxo: apesar de se apresentar como uma afirmação infinita, vindo daí sua força, essa infinitude é limitada. Apesar de infinita, é marcada pela finitude. Uma finitude infinita, ou uma infinitude localizada (finita). Trabalhando dentro do escopo da teoria freudiana da castração (Lacan 
posteriormente vai propor que ultrapassemos essa teoria), diríamos que, para que o Um se faça presente, seria necessário nele um ponto de inconsistência. A consistência exigiria um ponto constitutivo de inconsistência, ponto este tematizado por Freud, em outros momentos, sob o nome de castração.

Colocar-se-ia então, de imediato, a seguinte questão para o sujeito: como lidar com uma consistência inconsistente? Se aquilo que nos funda (e é de fundação que estamos falando) apresenta-se inconsistente, como garantir nossa existência? Essa operação de expulsão deve assim ser negada, sob pena de colocar em suspeição nossa referência primordial. Da mesma forma que a Austossung se apresenta como sendo a operação necessária para que a Bejahung possa se fazer presente enquanto Um, a negação (sucessora da Austossung) seria a forma possível de a Bejahung se produzir como efeito no campo da consciência. O "não", ao negar a castração, viabiliza, às avessas, a existência de uma Bejahung castrada. E será em cima de negações da castração que Freud irá construir sua teoria, negações que poderão ir desde a mais completa rejeição (psicose) até formas menos radicais, onde tentar-se-ia, por diferentes meios, mantendo a Bejahung, suprimir o que nela reatualiza a castração (neurose e perversão).

$\mathrm{Na}$ neurose, com o recalcamento da castração, entra em cena a denegação (Verneinung), onde, graças a uma separação entre o intelectual e o afetivo (Freud, 1925/1976: 296), criam-se as condições para que uma afirmação primordial castrada (posto que sem o afeto) possa de alguma forma circular no campo da consciência. Já na perversão, como forma de recusa (Verleugnung) da castração, algo ficticiamente é colocado no lugar desta, passando a existir, localmente, uma espécie de inversão de sinais: onde havia uma falta, passa a apresentar-se agora uma presença intensamente afirmativa, como se aquilo que fosse inapresentável tivesse, paradoxalmente, se transmutado em apresentação direta. De qualquer forma, em ambas as situações (neurose e perversão), mesmo que sob a marca de uma negação, a operação de Austossung é preservada, o que garante a existência de uma Bejahung castrada.

Na psicose, poderíamos dizer que a luta contra a castração teria sido de tal forma eficaz que chegaria a eliminá-la completamente do campo, sobrando apenas uma pura afirmação infinita, império do gozo, anulando qualquer possibilidade de existência de um sujeito. Se, na luta para manter-se como sujeito, o psicótico conseguir estabelecer uma finitude nessa afirmação desmesurada (por exemplo, corporificando-a em um objeto externo e cerceando-a dentro dos limites espaciais deste), essa referência, apesar de menos invasiva, mostrar-se-á vulnerável a qualquer paradoxo que coloque em evidência o necessário ponto de inconsistência que toda consistência deveria ter para se constituir, ponto este foracluído na psicose. Ou 
seja, ao rejeitar a castração, sobraria ao psicótico uma problemática Bejahung não castrada, situação frágil para garantir sua existência enquanto sujeito.

Um fenômeno freqüentemente observado na clínica seria aquele nomeado por Freud como o negativismo dos psicóticos (Freud, 1925/1976: 300). Segundo ele, haveria aqui "uma desfusão de instintos efetuada através de uma retirada dos componentes libidinais" (idem). Ou seja, trata-se de uma separação, de uma disjunção entre as duas correntes (a que afirma e a que nega). Lacan, em um dado momento, fala da "liberdade negativa de uma palavra [parole] que renunciou a se fazer reconhecer" na loucura, objetivando o "sujeito numa linguagem não dialética" (Lacan, 1954/1998: 281). Poderíamos entender aqui, nessa "liberdade negativa", não uma negação a toda e qualquer referência, mas especificamente àquelas oferecidas pelo Outro. O psicótico se coloca em posição de recusa absoluta, podendo, por exemplo, isolar-se em seu mutismo, ou adotar uma posição irônica, pontuando a inconsistência de todas as referências que lhe são apresentadas, o que o preservaria livre para uma referência imanente, não dialetizável, subtraída aos discursos. Nessa liberdade negativa do psicótico não se trata de uma inexistência de sujeito, mas de uma exclusão em relação ao social, onde um sujeito se constitui no próprio ato de subtração, em disjunção com o Outro. Esse aspecto disjuntivo, de fora-do-discurso, ganhará uma outra dimensão a partir da assim chamada segunda clínica de Lacan, tornando-se referência para a inscrição de todo e qualquer sujeito, e não apenas da psicose.

\section{Primeira e SEgunda Clínicas de LaCAN}

Se até o momento a formalização das questões envolvidas tem se mostrado difícil, as coisas ficam ainda mais complicadas quando entram em questão as diferenciações que haveria entre as chamadas primeira e segunda clínicas de Lacan. Não se trata, ao que tudo indica, simplesmente de um maior esclarecimento de formalizações. Parece que nessa virada ocorre algo próximo à consolidação de uma outra lógica, apesar de esta já estar presente, de maneira nuançada, desde o início do percurso de Lacan.

Segundo Zizek, o primeiro Lacan seria hegeliano, entendendo "o fim da análise como saber tudo, a mediação de todo conteúdo particular no meio simbólico universal" (Zizek, 2004: 38-9). Talvez faltasse nesse momento uma teoria mais acabada sobre a singularidade, havendo uma certa crença na capacidade de que, com o processo analítico, normalizar-se-ia o sintoma. Célio Garcia propõe que, nesse momento, "quando Lacan parecia atrelado a um simbólico a priori" (Garcia, 2002: 308), pensava-se "que o sujeito se realizava uma vez atingido re- 
conhecimento da ordem simbólica" (ibid: 313). O sintoma estaria separado da pulsão, resolvendo-se "no nível da linguagem" (ibid). Mergulhado nas elaborações de Saussure e nas questôes trazidas pela teoria do significante, para Garcia, um significante que se tornou fundamental nesse primeiro período foi o da "barra" (ibid: 308-9). Entre o significado e o significante, entre o Desejo da Mãe e o Nome-do-Pai, entre a verdade e a metáfora, temos sempre a barra, marca de uma impossibilidade de acesso. O que ficava embaixo poderia ou ser suprimido, ou, por meio de um ultrapassamento da barra, metaforizar-se. A neurose seria o império da metáfora, e alguns dos principais termos dessa fase, como o Nome-do-Pai e o sintoma, seriam do registro da metáfora. O grande problema da psicose seria a dificuldade em metaforizar, com o conseqüente comprometimento da metáfora do Nome-do-Pai. A metáfora seria, por excelência, a maneira de se negar algo, porém preservando seus efeitos. Tudo aquilo que fosse constitutivo do sujeito, mas que para a existência deste devesse ser negado, rechaçado, poderia se fazer presente por meio de metáforas. Assim, do impossível Desejo da Mãe (DM) obteríamos a metáfora do Nome-do-Pai (NP); da verdade da castração, obteríamos o sintoma. Estaríamos aqui na lógica do binarismo, compatível com a lógica tradicional e com a dicotomia entre o universal e o particular (ibid: 312-3). Faltaria, nesse período de Lacan, um melhor discernimento sobre a lógica do singular.

\section{O SINGULAR, O PARTICULAR E O UNIVERSAL}

Estes três temas (singular, particular e universal) possuem larga discussão lógico-filosófica, sendo amplamente trabalhados por Hegel. Não vamos entrar nessa discussão, atendo-nos a algumas articulações que poderíamos fazer a partir de elaborações de certos conceitos matemáticos propostos por Alain Badiou em seu livro $O$ ser e o evento.

$\mathrm{Na}$ linguagem matemática da teoria dos conjuntos, normal é algo que é "ao mesmo tempo apresentado na situação e representado pelo estado da situação", ou seja, ele "é, ao mesmo tempo, um elemento e uma parte" (Badiou, 1996: 395). Poderíamos propor que aquilo que chamamos de Universal seria o que se colocasse como completamente normal, onde todos os termos fossem simultaneamente elemento e parte do Todo, não havendo espaço para nenhum excesso. Excrescência, diferentemente da normalidade, é algo que é "representado pelo estado da situação sem ser apresentado pela situação", ou seja, ele "é uma parte, mas não um elemento. A excrescência toca o excesso" (ibid: 390). Em oposição à excrescência, teríamos a singularidade, que seria aquele termo "apresentado (na situação), mas 
não representado (pelo estado da situação)", ou seja, ele “é um elemento, mas não uma parte" (ibid: 398).

Na excrescência nós temos um excesso que não se apresenta como elemento, mas que, em decorrência de ter um predicado, faz parte do Todo. Tomemos como exemplo um paciente com sintomas obsessivos graves. Esse sujeito vai fazer parte de um conjunto de pessoas que têm um predicado em comum: serem portadores de sintomas obsessivos (lavar as mãos compulsivamente após usar o vaso sanitário, conferir inúmeras vezes as fechaduras de portas e janelas, etc). Há, nessas pessoas, um excesso que se representa de maneira similar, o que permite agrupálas em um conjunto. Falta, porém, algo que possibilite que venhamos a discernir os pacientes entre si. Nós podemos identificá-los como sendo um grupo, ou parte de um Todo, mas nada nos permite distingui-los individualmente enquanto sujeitos. Na clínica, "tratamos os sintomas como particulares, enquanto, no nível do sujeito, introduz-se o singular" (Garcia, 2002: 313).

Essa aproximação entre o sintoma psicanalítico e a definição matemática de excrescência, apesar de factível, faz mais sentido quando levamos em conta as últimas teorizações de Lacan. Entender o sintoma como "mensagem referida a um código, mensagem a interpretar" da primeira fase lacaniana, é diferente do que concebê-lo como o "dispositivo de gozo" (Garcia, 2002: 308) das teorizações finais. A distinção desenvolvida aqui por Badiou, dentro do escopo da teoria dos conjuntos, entre apresentação e representação, não comunga da mesma lógica daquela em jogo na concepção de barra da primeira clínica. Dizer que o sintoma é do registro da metáfora não é a mesma coisa que dizer que ele se representa mas não se apresenta. Não é possível escrever apresentação e representação separadas por uma barra, como fazemos com o significado (embaixo) e a metáfora (em cima). Mas, de qualquer forma, se a definição de excrescência aparentemente encontra-se mais em consonância com o sintoma da segunda clínica, ela não é totalmente estranha ao que poderíamos entender como sendo o sintoma das fases iniciais de Lacan. Em ambas poderíamos falar do sintoma como sendo um excesso localizado, portador de um predicado, que se manifesta, repetitivamente, sempre da mesma forma. Porém, e agora chegamos ao ponto que nos interessa, quando olhamos o que ambas propóem como sendo o destino que se deseja para o sintoma durante o tratamento, aí sim as diferenças tornam-se marcantes. Na primeira clínica, às voltas com um simbólico poderoso, Lacan parecia direcionar-se para algo que poderíamos aproximar com a normalização da excrescência. De um excesso que incomoda, faz sofrer, por meio da análise conseguiríamos dar a ele uma explicação, absorvendo-o completamente na lógica da linguagem. Já na segunda clínica, às voltas agora com o real e os dispositivos de gozo, o objetivo final 
da análise não seria normalizar o excesso, mas dar a ele uma voz singular. A promessa subentendida ao analisante de que no final do processo analítico todas as causas do sintoma se esclareceriam não passaria de um engodo. $\mathrm{O}$ objetivo da análise na segunda clínica de Lacan seria o de, a partir de algo que se representa mas não se apresenta (sintoma), obtermos uma apresentação que não se representa (singularidade).

Uma singularidade, por não fazer parte do Todo, apresenta-se como sendo um "Um disjunto do universal" (Garcia, 2002: 313). Com o processo analítico, ao trabalharmos um excesso incluído no Outro (sintoma), obteríamos, por meio da criação de um nome próprio (não predicável), uma posição de disjunção radical (singularidade). Sintoma e singularidade, apesar de similarmente terem por função dar tratos ao excesso, seriam formas distintas de se lidar com ele. $\mathrm{O}$ sintoma predica o excesso, marcando sua face finita, repetitiva, enquanto que a singularidade, ao dar-lhe um nome próprio, disjunto de qualquer predicação, liberta-o de toda e qualquer determinação a priori. Nessa concepção, um sujeito, enquanto que determinado por uma singularidade, só poderia existir fora do sistema (exsistir). Como dissemos acima, Badiou utilizou o termo "subtração" (Badiou, 2005: 98) para falar dessa ex-sistência do sujeito, que se constituiria em disjunção ao simbólico universalizante de nossa contemporaneidade. Talvez aqui possamos entender melhor a expressão "foraclusão generalizada" proposta por Miller ao falar da impossibilidade de comunicação. Em uma cultura em que o simbólico ganhou autonomia, onde, por exemplo, a reprodução da espécie deixou de ser privilégio do corpo para tornar-se matematizada, controlada em laboratórios, nós nos encontramos na desconfortável situação de submissão a um Outro desencarnado, incapaz de nomear o excesso, ou mesmo de reconhecê-lo como tal ${ }^{3}$. Nessa sociedade foracluída, marcada por um excesso difuso, não localizável (os diagnósticos desse excesso ilocável proliferam: ansiedade generalizada, síndrome do pânico, agorafobia, fobia social, etc), cabe à psicanálise, em contraposição, oferecer a possibilidade do sintoma e a conseqüente inclusão do excesso. A partir dessa inclusão (e, sob esse aspecto, o sintoma não deixa de ser uma espécie de solução), poderíamos então dar início ao processo analítico, que teria por fim a constituição (e defesa) de uma singularidade.

\section{INACABAMENTO}

Voltando às questôes que deram início a este texto, como entender a dupla afirmação/negação dentro do escopo da segunda fase de Lacan? Já propusemos acima a existência de uma lógica binária, impregnante no primeiro período de 
Lacan, que não se manteria no segundo período. Neste último, a operacionalidade da barra deixaria de ter função, e a concepção de metáfora perderia sua importância. A diferença entre neurose e psicose, uma no reino da metáfora, a outra vendo comprometida essa capacidade de metaforização, se esvaeceria. As atenções voltam-se então para a psicose. Desde o início a teoria tentava entender, nela, a constituição de um sujeito que se desse independentemente do processo de metaforização. Com a segunda clínica começa-se a perceber que muito do que foi postulado para as psicoses poderia ser estendido para a concepção do sujeito em geral, não importando sua estrutura. A referência fundadora do sujeito não mais estaria atrelada a uma lógica binária, dialética, mas a uma lógica da imanência, onde uma afirmação se imporia sem passar pela negativa, dispensando-a. Célio Garcia propõe como sinal gráfico para essa fase a seta $(\rightarrow)$, tendo em um de seus pólos o "não-todo" (singular, pois lhe falta a predicação que o definiria), e no outro o "para todos" (portadores da predicação que define universalmente a todos):

$$
\text { “não todo" } \rightarrow \text { “para todos” (Garcia: 314) }
$$

Previamente à inscrição do "não-todo", como condição para a constituiçãoo de um sujeito, teríamos o sintoma, dispositivo de gozo (afirmação pura?). Segundo Badiou, o sintoma teria uma anterioridade em relação ao evento (événement) (Badiou, 1996: 178), este último sendo aquilo que se apresenta como singularidade na fundação da história de um sujeito. Ou seja, o sintoma é a profecia de um sujeito por vir. Após sua apreensão em termos de singularidade, retroativamente poderíamos identificar um sujeito que estaria lá, no sintoma, por acontecer.

A singularidade, porém, inscrição que se coloca como afirmação de um sujeito e que tem a urgência de um excesso agora nomeado, não deixaria também de carrear algo que poderíamos aproximar com o registro da negação. A ela é vedada a predicação, o que lhe dá o caráter de "não-toda". Em decorrência dessa impossibilidade de representar-se (não tendo predicado, ela não pode fazer parte do Todo), a singularidade institui-se em posição de subtração (negação) ao Outro.

Na segunda clínica, se formos aproximar a "afirmação" com os dispositivos de gozo, poderíamos ver no Outro desencarnado aquilo que tentaria colocar-se como império do saber, campo por excelência da "negação". É na disjunção a esse Outro que um sujeito pode ex-sistir.

Jean-Luc Nancy, em texto publicado em 2003, propõe trabalharmos com o termo "inacabamento" [inachèvement]. Segundo esse autor, Freud seria não o formulador de uma terapêutica, mas um pensador da finitude. À infinitude da 
consciência, Freud teria inscrito uma finitude, que seria o inconsciente (Nancy, 2003: 151). A verdade do pensamento é o inconsciente, estando nele, portanto, a determinação dos limites da consciência. Ao apresentar-se como "o fim da consciência", ou "o fim da significação" (ibid: 146 [tradução minha]), o inconsciente seria aquilo que daria ao pensamento o caráter de processo inacabado, condenado ao inacabamento. Tratar-se-ia de uma finitude infinita, ou, dizendo de outra forma, de uma infinitude localmente situada. Na prática analítica, é sobre o lugar vazio do analista que se inscreve essa finitude eterna (inacabável).

Aquilo que interdita a finitude de se totalizar é a impossibilidade de sua predicação. Apesar de se apresentar, ela está condenada ao inacabamento de uma representação impossível. Do Édipo freudiano, onde as negações se dariam sobre a castração, tentando negar a falta constitutiva da afirmação, chegaríamos, no final do percurso de Lacan, a um "além do Pai", onde o que se nega não é uma falta constitutiva (castração), mas a possibilidade de uma "normatização" do excesso $^{4}$. Se, na primeira clínica de Lacan, a verdade tem que ficar sob a barra, na segunda clínica ela pode apresentar-se em si, como finitude infinita (marcada pelo inacabamento). Não se trata mais de uma barra que nos obriga à metaforização da verdade do inconsciente, mas de uma verdade que se apresenta condenada ao inacabamento. Vemos assim a proximidade dessas formulaçóes com a psicose das primeiras elaboraçôes de Lacan, onde a referência fundadora, estando no registro de algo que se apresenta de forma enigmática, implica um sujeito disjunto, engajado na construção de um mundo que visaria, sem jamais conseguir, dar sentido a uma inscrição inassimilável.

\section{REFERÊNCIAS BIBLIOGRÁFICAS}

Badiou, A. (1996). O ser e o evento. Rio de Janeiro: Jorge Zahar Editor.

. (1997). Deleuze - o clamor do ser. Rio de Janeiro: Jorge Zahar Editor. . (2005). Le siècle. Paris: Seuil.

Ewald, F. (1986). L'état providence. Paris: Grasset.

Freud, S. (1924/1976). Neurose e psicose. Em ESB, vol. XIX (pp. 187-193). Rio de Janeiro: Imago.

—. (1925/1976). A denegação. Em ESB, vol. XIX (pp. 293-300). Rio de Janeiro: Imago.

Garcia, C. (2002). Lacan e companhia. Em Safatle, V. (Org.). Um limite tenso (pp. 30529). São Paulo: UNESP. 
Lacan, J. (1998). Escritos. Rio de Janeiro: Jorge Zahar Editor.

Laplanche, J. e Pontalis, J.-B. (1986). Vocabulário da psicanálise. São Paulo: Livraria Martins Fontes Editora Ltda.

Miller, J.-A. (1993). Forclusion généralisée. Cahier ACF-VLB, 1, automne.

Milner, J.-C. (1996). A obra clara. Rio de Janeiro: Jorge Zahar Editor.

Nancy, J.-L. (2003). Das unendliche ende der psychoanalyse. L'animal. Litteratures, arts et philosophies, 14/15, 145-51.

Zizek, S. (2004). Le devenir-lacanien de Deleuze. Em Iannini, G., Rocha, G. M., Pinto, J. M., Safatle, V. (Orgs.). O tempo, o objeto e o avesso (pp. 17-40). Belo Horizonte: Autêntica.

\section{Notas}

1 Conforme nos mostram Laplanche e Pontalis (Laplanche e Pontalis, 1986: 574), Freud em alguns momentos parece manter uma correlação entre as concepções de retração de investimento e de significação, como podemos ver, por exemplo, no texto Neurose e psicose, de 1924 (Freud, 1924/1976: 191).

2 Para melhor compreender as concepções de Letra e matema em Lacan, aconselho o livro $A$ obra clara de Jean-Claude Milner (Milner, 1996).

3 Um outro exemplo desse Outro desencarnado são as pulseiras eletrônicas utilizadas por certos criminosos nos EUA. Eles podem ficar fora da prisão, desde que sua localização seja monitorada 24 horas por dia.

4 Preferimos utilizar o termo "normatização" ao invés da "normalização" da teoria dos conjuntos, para colocarmos-nos em consonância com tese proposta por François Ewald ao fazer diferenciação, no Estado democrático, entre Lei e norma (Ewald, 1986).

Recebido em 3 de setembro de 2005 Aceito para publicação em 29 de março de 2006 